\title{
"The marketing strategy for making optimal managerial decisions by means of smart analytics"
}

\begin{tabular}{|c|c|}
\hline AUTHORS & $\begin{array}{l}\text { Andrii Butyrskyi iD https://orcid.org/0000-0002-3225-7017 } \\
\text { R http://www.researcherid.com/rid/T-6709-2018 } \\
\text { Natalia Burkina id https://orcid.org/0000-0003-2993-5128 } \\
\text { Yurii Popovskyi iD https://orcid.org/0000-0001-9446-5287 }\end{array}$ \\
\hline ARTICLE INFO & $\begin{array}{l}\text { Serhii Kozlovskyi, Larysa Shaulska, Andrii Butyrskyi, Natalia Burkina and Yurii } \\
\text { Popovskyi (2018). The marketing strategy for making optimal managerial } \\
\text { decisions by means of smart analytics. Innovative Marketing , 14, 1-18. } \\
\text { doi:10.21511/im.14(4).2018.01 }\end{array}$ \\
\hline DOI & http://dx.doi.org/10.21511/im.14(4).2018.01 \\
\hline RELEASED ON & Monday, 10 December 2018 \\
\hline RECEIVED ON & Friday, 02 November 2018 \\
\hline ACCEPTED ON & Wednesday, 05 December 2018 \\
\hline LICENSE & $\begin{array}{l}\text { This work is licensed under a Creative Commons Attribution } 4.0 \text { International } \\
\text { License }\end{array}$ \\
\hline JOURNAL & "Innovative Marketing " \\
\hline ISSN PRINT & $1814-2427$ \\
\hline ISSN ONLINE & $1816-6326$ \\
\hline PUBLISHER & LLC “Consulting Publishing Company "Business Perspectives" \\
\hline FOUNDER & LLC “Consulting Publishing Company "Business Perspectives" \\
\hline
\end{tabular}

Serhii Kozlovskyi iD https://orcid.org/0000-0003-0707-4996

R http://www.researcherid.com/rid/P-3856-2017

Larysa Shaulska (D https://orcid.org/0000-0002-7919-6733

Andrii Butyrskyi iD https://orcid.org/0000-0002-3225-7017

R http://www.researcherid.com/rid/T-6709-2018

Natalia Burkina iD https://orcid.org/0000-0003-2993-5128

Serhii Kozlovskyi, Larysa Shaulska, Andrii Butyrskyi, Natalia Burkina and Yurii decisions by means of smart analytics. Innovative Marketing , 14, 1-18. http://dx.doi.org/10.21511/im.14(4).2018.01

RELEASED ON

ACCEPTED ON Wednesday, 05 December 2018 License

NUMBER OF REFERENCES

30

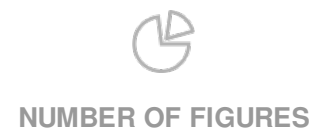

7
NUMBER OF TABLES

2

(C) The author(s) 2022. This publication is an open access article. 


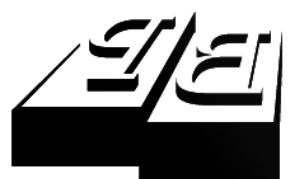

BUSINESS PERSPECTIVES

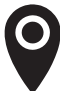

LLC "CPC "Business Perspectives" Hryhorii Skovoroda lane, 10, Sumy, 40022, Ukraine

www.businessperspectives.org

Received on: $2^{\text {nd }}$ of November, 2018 Accepted on: $5^{\text {th }}$ of December, 2018

(C) Limited Liability Company "Consulting Publishing Company

"Business Perspectives", 2018

Serhii Kozlovskyi, D.Sc. (Economics), Professor, Vasyl' Stus Donetsk National University, Ukraine.

Larysa Shaulska, D.Sc. (Economics), Professor, Vasyl' Stus Donetsk National University, Ukraine.

Andrii Butyrskyi, D.Sc. (Juridical Science), Associate Professor, Yuriy Fedkovych Chernivtsi National University, Ukraine.

Natalia Burkina, Ph.D. (Pedagogical Science), Associate Professor, Vasyl' Stus Donetsk National University, Ukraine.

Yurii Popovskyi, Ph.D. (Pedagogical Science), Vasyl' Stus Donetsk National University, Ukraine.

Serhii Kozlovskyi (Ukraine), Larysa Shaulska (Ukraine), Andrii Butyrskyi (Ukraine), Natalia Burkina (Ukraine), Yurii Popovskyi (Ukraine)

\title{
THE MARKETING STRATEGY FOR MAKING OPTIMAL MANAGERIAL DECISIONS BY MEANS OF SMART ANALYTICS
}

\begin{abstract}
The article presents a methodology for developing the marketing strategy for making optimal managerial solutions by means of smart analytics. Such issues as marketing strategy modeling methods; software products based on the integration of smart analytics; optimal choice of electromobile and others have been considered. The main subject of the article is constructing an optimal decision-making model using a combination of classical statistical and mathematical methods and models, as well as modern information technologies, including methods of smart analytics. The conceptual scheme of the effective marketing management has been created according to the structural components: information, statistical, mathematical, analytical and technological, etc. The structure and main features of every component have been considered in detail. The created conceptual scheme of the effective management was demonstrated through the simple example of optimal choice of electromobile. To investigate sales on electro mobiles in the Ukrainian market, a set of factors has been considered. According to them, the correlation and cluster analyses have been conducted. The main factors, which are the most influential for the price of electromobile in the Ukrainian market, have been revealed. All considered models of electromobiles have been divided into three groups depending on the characteristics price - quality.
\end{abstract}

\section{Keywords}

\section{JEL Classification $\quad \mathrm{A} 1, \mathrm{C} 1, \mathrm{C} 5, \mathrm{C} 6, \mathrm{C} 8$}

\section{INTRODUCTION}

There is high uncertainty of subject's economic behavior under market economy. Therefore, in such situation, an important role is played by the methods of the perspective analysis allowing to make administrative decisions based on assessment of possible situations in the future and on the choice among several alternative versions of decisions.

Development and implementation of efficient administrative decisions are the most important preconditions of organization's production competitiveness in the market and creation of organization's optimum structure, conducting the reasonable personnel policy and rationalization of other activity aspects of the organization. Non-optimum administrative decisions lead to the negative economic and social events. It must be kept in mind that the choice of accurate and efficient administrative decision represents the result of complex of economic, organizational, legal, informational, technical, logical, mathematical, psychological and other aspects.

In conditions of strengthening of the competition in the market, requirements to efficiency and qualities of the made decisions increase 
even more. Effective management becomes impossible without quality analysts, because success of any economic process depends on a qualitative analysis. Fast introduction of the modern technologies, emergence of new employment spheres, transition from traditional human society to informational considerably increase the importance of innovations, using social and economic transformations, as well as various latest technologies in each expert activity.

\section{LITERATURE REVIEW}

Abelein, Lochne, Hahn, and Straube (2012) investigated more than 7000 semiconductor elements that would secure safety, comfort and transmission of cars. These numbers will grow sharply, when turning from an ordinary car to the electronic machine.

Afuah (2003) created the two-dimensional classification chart that lights up ten different approximate measures of business efficiency in research of strategy being implemented. A chart allows to classify exhaustive illumination of measuring approaches and determination of their comparative advantages and defects.

Atteslander (2008) worked out methods of empirical social researches. He offered the comprehensive and clear idea about a multidimensional stumper with many examples and graphic arts of "Atteslander".

Baden-Fuller and Morgan (2010) conducted research in history and science philosophy, with the special reference to the sources of literature, where the use of models was examined in biology and economy. They indicated advancing in the different forms of models: in providing facilities for description and classification of business; in functioning as bases for scientific researches; in coming forward as recipes of creative managers.

Basl (2004) investigated innovation of business processes based on IS/ICT and TOC in the center of researches realization of the informative systems in the basis of electro transport.

Bowley (1926) was measuring the accuracy of data that had arrived at sampling. He was the first researcher who large-scaled theoretical inspection of selective inspections. He also examined arguments in the context of theory of statistical conclusion.
Caceres and Paparoidamis (2007) created the theoretical basis for the estimation of strategic increase of consumers image about quality of service or product, in particular, from the point of view of improving the mutual relations and loyalty of clients in B2B and data to check this theoretical base.

Chern, Anthony, and Chih-Ping (2014) developed the theory and methodology of "Analysis of data conducted for marketing secret service", informative systems and electronic business, as well as modern methods of data and treatment definition of the information systems.

Colgate and Lang (2001) created the investigational methods and the methods of empirical verification of intercommunications between quality of customers service and commodities. A research model about the intercommunication between quality of service, satisfaction of clients and their loyalty was established.

Dombrowski and Engel (2014) investigated cars mobility changings and influence on entire chain of supply and concentrated mainly on problems in a primary commodity sector, such as development of electric transport vehicles, technological basic problems (for example, technology of batteries) or infrastructure.

Forster, Zapp, Aelker, Westkämüer, and Bauernhansl (2013) considered the chains of motor supply and semiconductor industry. They found weak points, which were appraised on intercommunications between these two industries. The standard model appointed as a tool of measuring for the general management of cost in motorcar and semiconductor industry was presented by researchers based on this analysis.

Teece (2010) analyzed the business model, that described a design or architecture of mechanisms production, the transmission and creation of cost objects, that he used in a car production. 
Supreme Council of Ukraine (2018) proposed The Project of Law on making alteration in the Internal revenue code of Ukraine in relation to providing the balance of budgetary receivables in 2018. Amendment 201 states that import to Ukraine of the transport vehicles, equipped exceptionally by electric engines, is free from charging an excise tax until December 31, 2022.

\section{RESEARCH OBJECTIVE AND METHODOLOGY}

The purpose of the research is theoretical justification and development of marketing strategy modeling methodology, which optimizes administrative solutions with the smart analytics tools. It might be directed to increase the effectiveness of different types of activity functioning.

According to the research purpose, the following tasks have been formulated:

- to reveal principal components of making optimal administrative decision for marketing strategy;

- to provide the characteristics to each founded component;

- $\quad$ to develop methodology of making optimal administrative decision's marketing strategy;

- to provide theoretical justification of the developed methodology;

- to demonstrate a capability of using proposed methodology on the example of selling and buying the electromobile.

The important factor of the goal's successful achievement is the overview of the existing knowledge and receiving a clear data in every professional sphere. It is well-known that successful business is based on needs of buyers. Without demand on production, the meaning of this or that branch does not exist. Under a big competition, advertising campaigns and business offerings, an important factor of future advance of goods is obtaining information about behavioral characteristics of buyers. Special attention is paid to supporting the client.
Each manager deals with various tasks every day. They need to make a lot of decisions very quickly. So, very often they do it based on intuition. The main supporting tool for decision-making in daily chief's activity must become the software for modelling the organizational systems operation and their elements. Thus, in order to increase the effectiveness of enterprise's activity, it is necessary to organize qualitative analytics for all processes taking place at the enterprise. Achievement of this purpose is impossible without introduction of the corresponding analytical tools, which are based on smart analytics tools. It proves the relevance and the practical importance of the given research.

Nowadays, many studies on the managerial decisions making have already been done. One of the most popular is the graphic model, proposed by Victor Vroom and Philip Yetton, which was later substantially complemented by Arthur Yago. This model proposes to determine an effective leadership style, depending on the situation. It is also assumed that the same leader can use different styles. The main feature of this model is its focus on only one aspect of leadership behavior. This very aspect lies in involving subordinates in decision-making. The Vroom-Yetton model of choosing the optimal decision-making process is based on seven factors:

1. Compliance with requirements for the decision quality.

2. Knowledge of the person making the decision.

3. Structuring the problem.

4. Independence of subordinates' actions.

5. The authority of the decision maker.

6. The unity of head's and subordinate's goals.

7. The possibility of the conflict between employees about a decision that should be made.

However, in this paper, the emphasis has been placed on constructing an optimal decision-making model using a combination of classical statistical and mathematical methods and models, as well as modern information technologies, including methods of smart analytics. Figure 1 shows 


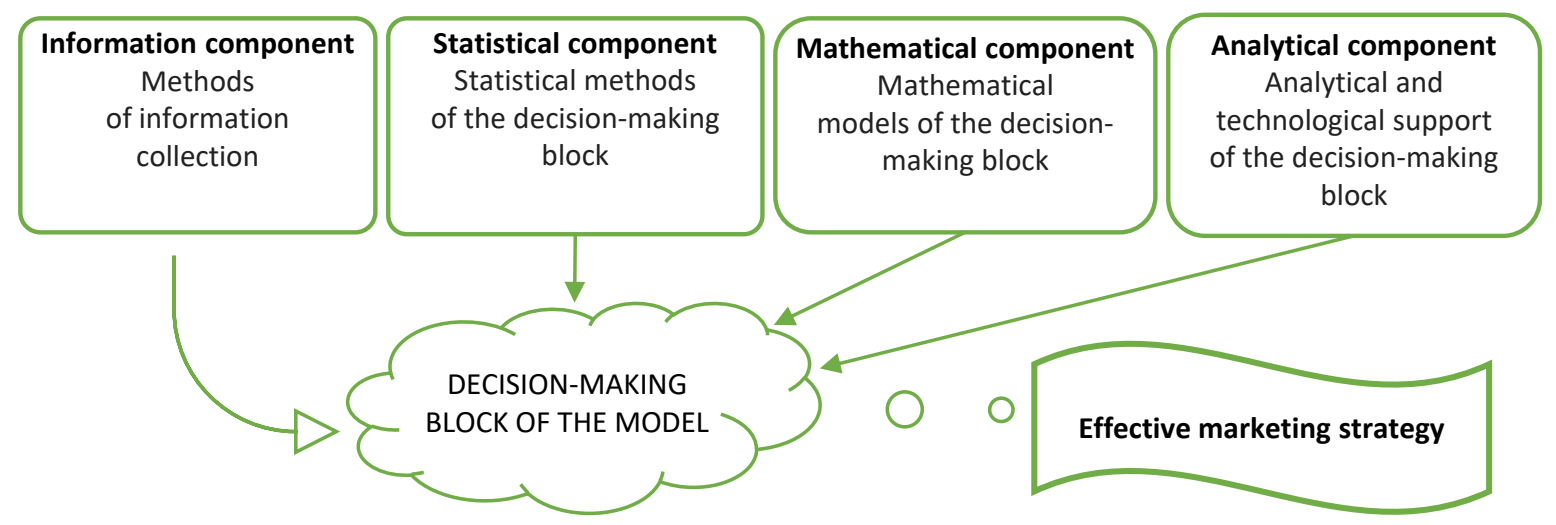

Figure 1. The conceptual scheme of the effective marketing strategy

the conceptual scheme of the effective management according to considered structural components. Its main parts are reviewed below.

\section{THEORETICAL PART}

\subsection{Information component}

A model of developing the marketing strategy allows completing a lot of different tasks. The following ones are among them:

- precise identification of the marketing strategy results;

- evaluation of their meaning for business;

- identification action's order in the business processes;

- recourses identification for business processes;

- identification of the interaction between business model components; automatization of the whole business process or its parts;

- description the business activities throw the marketing model;

- decision-making according to the marketing model.

As it can be seen, the information is the main part of all processes in the given tasks. Without information it's impossible to answer on these questions and to have any result. Though, only optimal result is needed. That is why the information must be addressed first. On the basis of demands given below, the following issues for the informational component have been formulated (Figure 2).

Alternatives to managerial decisions should be brought into a comparable view on the following factors:

time factor (implementation time of projects or investments);

Source: Compiled by the authors.

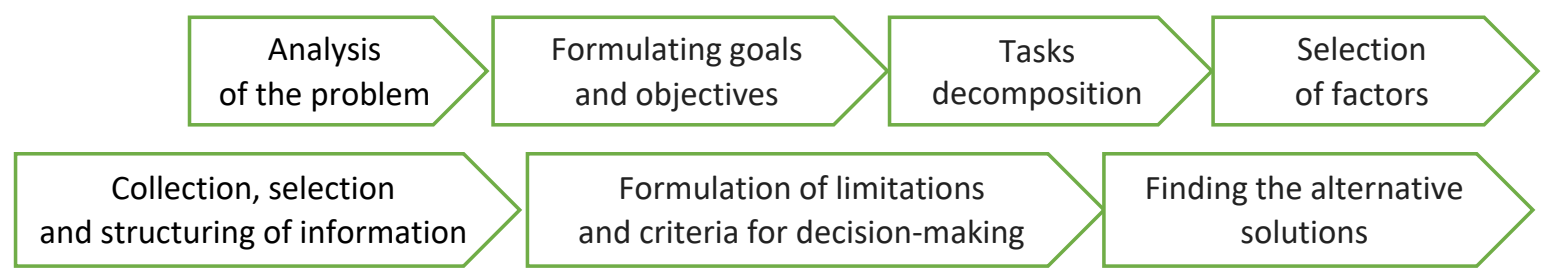

Figure 2. The main issues for the informational component 
- quality factor of the object;

- factor of obtaining information for the management decision;

- inflation factor;

- $\quad$ risk factor and uncertainty;

- factor influencing the development of managerial decisions.

Comparability of alternative managerial decisions on the listed factors is provided at substantiation of technical, organizational or economic measures for improvement of private indicators of quality and resource intensity of products, organizational and technical level of production, social development level of the collective and ecology problems.

In order to take into account a time factor when making managerial decisions, it is expedient to bring all costs to one year. Accounting method for this factor allows to calculate the size of the deposit in the present with a fixed contribution rate in the future.

Considering $a$ quality factor in the development of a management solution usually takes place in the value of the function of the investment object, price, cost, labor intensity, expenses.

$A$ factor for obtaining information for making a managerial decision, which significantly influ- ences decision-making, lies in availability of necessary information. Due to the existence of many factors affecting the quality of information, its significance often changes. In practice, frequently people collect any available information and then try to find some, which is needed at the definite time. When making a management decision, if one relies only on readily accessible and obvious information, one can make a serious mistake. It is also incorrect to assume that the amount of information is equivalent to its quality. Information management systems greatly increase the amount of information, but it often confuses the decision maker, though.

$A$ inflation factor considers depreciation of money and manifests itself in the form of rising prices for goods and services without raising their quality. When ensuring comparability of alternative management decisions, the inflation factor is recommended to be calculated by the formula:

$$
Y_{r}=Y_{n} \cdot J_{i},
$$

where $Y_{r}$ - the value of the function reduced to the new conditions by the level of inflation (price, investment, etc.), $Y_{n}$ - the nominal value of the same function, $J_{i}$ - inflation index for the analyzed period.

Risk and uncertainty factors are taken into account in the models, depending on the situation when developing an alternative management solution as follows. Management decisions are made under

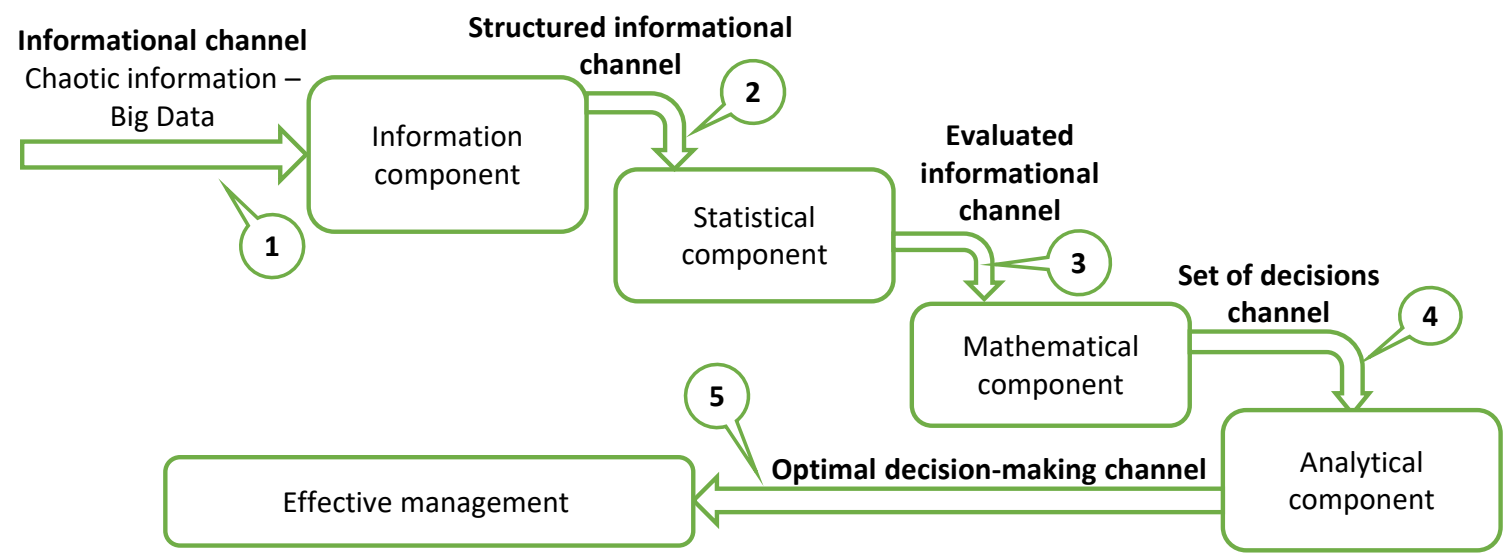

Figure 3. Informational channels structure at the conceptual scheme of the effective management 
different conditions, and their result can be predicted with different levels of certainty. Therefore, all managerial decisions are traditionally divided into decisions in terms of certainty, risk or uncertainty. Management decisions made in the conditions of certainty are made when the leader knows exactly the result of each of the alternative choices. Decisions made under risk conditions include those whose results are not specific, but the probability of each outcome is known. In the conditions of certainty for a managerial solution, there is only one alternative. The probability of occurrence of this or that phenomenon is objective, when it can be determined by economic-mathematical methods or by statistical analysis.

A factor influencing the development of managerial decisions are defined by analytical methods. Figure 3 shows all informational channels, which connect four main components of the conceptual scheme of the effective management.

\subsection{Statistical component}

Statistical methods are based on the use of information about the previous successful experience of organizations in any area of activity for the development or implementation of management decisions by other companies. These methods are utilized through the collection, processing and analysis of statistical materials. They can be both the result of real actions or worked out artificially by statistical modeling on a computer. These methods include: sequential analysis and the method of statistical tests. Probabilistic-statistical decision-making methods are used when the effectiveness of decisions made depends on factors that are random variables, for which the laws of probability distribution and other statistical characteristics are known. In this case, each decision can lead to single outcome from the variety of possible ones, with each outcome having a certain probability of occurrence, which can be calculated. The indicators characterizing the problem situation are also described with the use of probabilistic characteristics.

Statistical methods can be used both at the development stage and at the decision-making stage. At the development stage, after a preliminary decision has been made, it is discussed with col- leagues of its own or related enterprise to take into account their positive experience. Then the final decision is made. At the stage of selection of the final management decision, the employees of the enterprise already have a constantly updated set of management decisions. At the earliest stage of developing the solutions, employees use the positive experience of other organizations and consider its final management decision. Then this new solution with the results of implementation will also be included in the set of management decisions.

In practice, probabilistic and statistical methods are often used when the findings based on sample data are projected on the whole population. However, in this case, it is necessary to first estimate the possibility of obtaining sufficiently reliable probabilistic and statistical data in each specific situation.

The essence of probabilistic-statistical methods of decision-making consists in the use of probabilistic models on the basis of estimation and testing of hypotheses with the help of selective characteristics. The advantages of using these methods include the ability to take into account various scenarios for the development of events and their probabilities. Their disadvantage is that the values of scenario development probabilities used in calculations are usually very difficult to obtain. The application of a specific probabilistic-statistical decision-making method comprises three stages:

- transition from economic, managerial, technological reality to an abstract mathematical-statistical scheme, i.e. the construction of a probabilistic model of the management system, the technological process, the decision-making procedure, in particular, based on the results of statistical control, etc.;

- carrying out calculations and obtaining conclusions by purely mathematical means within the framework of a probabilistic model;

- interpretation of mathematical-statistical conclusions applied to the real situation and making an appropriate decision.

The most common probabilistic statistical methods are regression analysis, factor analysis, vari- 
ance analysis, statistical methods of risk assessment, scenario method, etc. The field of statistical methods, devoted to the analysis of statistical data of non-numerical nature, is becoming increasingly important, which is resulted by the measurements on qualitative and different types of factors. One of the main applications of non-numerical nature objects statistics is the theory and practice of expert assessments related to the theory of statistical decisions and problems of voting.

\subsection{Mathematical component}

Mathematical methods allow solving the tasks and problems of the organization's activity, which can be fully formalized. At the heart of this group of methods is the scientific and practical approach, which involves the selection of optimal solutions by processing large amounts of economic and other types of information. Their application is most effective when developing management decisions in the following cases:

- the goal or criterion of optimization is predetermined and clearly defined;

- the basic conditions for its achievement (limitations) are known;

- there is a choice of ways to solve the task, which means that the problems are well-structured.

There is a peculiarity of mathematical methods for justifying management decisions that lies in the existence of a specific algorithm that must satisfy three requirements:

1) certainty, i.e. accuracy and uniqueness;

2) mass nature, which means its universality, i.e. applicability for solving a class of problems, when the initial data can vary within certain limits;

3) effectiveness, i.e. the possibility of solving the problem for a finite number of operations.

There are many methods from this group that are aimed at solving typical tasks of the organizations' activities. Those of them that have now become most widespread will be mentioned.
1) Methods of mathematical analysis (differential, integral and calculus of variations) are used in traditional economic calculations when justifying the resource requirements, taking into account the costs of production and sales of products, developing plans and projects with balance calculations.

2) Methods of mathematical statistics are applied in those cases when the change in the analyzed indicators can be represented as a random process. Statistical methods play an important role, especially in predicting the behavior of economic and other performance indicators of the organization.

3) Econometrics methods are based on the synthesis of three areas: economy, mathematics and statistics. Their basis is the economic model, which is considered as a schematic representation of an economic phenomenon or process through the scientific abstraction by reflecting its main characteristic features.

4) Linear programming methods reduce most of the problems of the mathematical optimization models developed for practical application. Linear programming is based on solving a system of linear equations, when the relationship between the phenomena studied is strictly functional.

5) Dynamic programming methods are used to solve optimization problems, in which the objective function or constraints are characterized by nonlinear dependencies. For example, the economic efficiency of production increases or decreases disproportionately to a change in the scale of production; the cost of purchasing a batch of spare parts increases due to the increase in the size of the lot, but not proportionally to them.

6) Queue theory methods (optimal service) are used to find the optimal number of service channels at a certain level of demand for them. It is necessary to choose the optimal variant of customer service organization, in which the service time will be minimal, and the quality will be high, if there is no unnecessary cost. 
7) Investigating operations methods are based on the use of mathematical probability models. Optimization of solutions consists in a comparative study of numerical estimates of factors that cannot be estimated using conventional methods. Operations research methods are designed to find solutions that would be optimal for as many enterprises, organizations or their units as possible.

8) Situational analysis method is a complex technology for the preparation, adoption and implementation of a management decision, based on analysis of an individual managerial situation. Situational analysis is based on specific situations, problems that arise in the real activity of the organization, for which a management decision has to be made. However, the technologies of situational analysis make it possible to find managerial decisions not only in a specific situation. Based on a deeper analysis of situations, they allow the establishment of trends, patterns and factors that determine their development. Thus, it is more justified to make long-term management decisions, up to adjusting the organization's strategic goals.

9) The game theory method allows simulating situations, in which decisions should take into account the discrepancy between the interests of various entities and individuals. Mathematical models of game theory allow analyzing the identified alternatives to the actions of the organization, considering possible responses of competitors. Game models in business are used to predict the reaction of competitors to price changes, offer the organization the forms and methods of providing the additional services, supporting sales, modifying and assimilating new products.

10) "Tree" solutions method is a schematic representation of the decision-making problem. The decision tree gives a manager the opportunity to take into account the various directions of action, correlate financial results with them, adjust them according to the probability assigned to them, and then to compare the alternatives.

11) Time series analysis method is a method of identifying patterns and trends of the past and ex- tending them into the future. This method of analysis is often used to assess the demand for goods and services, assess the need for stocks, predict the structure of sales, characterized by seasonal fluctuations, or the need for personnel.

\subsection{Analytical component}

These methods are based on the work of a manager or a specialist with a set of analytical dependencies. They determine the relationship between the conditions of the task and its results in the form of formulae, graphs, logical relationships. In each specific case, the decision-making method is chosen based on the task, the available initial data, the available task models, the decision-making environment, the decision-making process, the required accuracy of the solution, and the analyst's personal preferences.

In order to make a choice among alternatives from the considered set, it is necessary to evaluate them first. Moreover, it must be done according to the effectiveness criteria. There are two main types of such criteria, which are called "optimality criterion" and "fitness criterion". Criteria for optimality are used to make optimal decisions that ensure maximum effectiveness of the operation. The suitability criteria are used to make satisfactory decisions that ensure the required effectiveness of the operation.

Using the optimality criterion means that the management decision is considered optimal if it ensures maximum efficiency. The suitability criterion is used to make decisions that meet the eligibility requirements in accordance with the concept of limited rationality. Management decision is considered satisfactory if it provides the required efficiency of the operation. Consequently, the fitness criterion is the decisive rule, according to which decisions are made only if they provide the required, but not necessarily the maximum, efficiency of the operation. If there are several such solutions, then it is considered that they are all the same in preference and the person does not care which one to choose. Usually, in this case, a decision that corresponds to personal preferences is made.

Some elements of the given approach were considered on the practice in the papers (information, statistical, mathematical and analytical components). 
The abovementioned information is a data of a multi-format nature, which practically does not allow the processing of all received masses of information, as it is impossible due to the complexity of the combination. For automation of economic calculations in modern business structures, software products, such as client-database built on different types of structural bases, are used. On the other hand, the survey of buyers can be random and not structured.

To study the data of a heterogeneous nature, the introduction of business intelligence systems that are part of the class of information systems is optimal for economic structures, which allow turning the scattered and raw data into structured information and knowledge, used in management. This information is the basis of specialized software tasks, which is business analysis (BI).

Systems of business analysis, further BI, is a class of systems designed for various analytical data processing, which contains sets of mathematical, financial and statistical functions for forecasting, identifying trends, assessing situations and planning.

The heads of the enterprises determine the main task of business management in the complex monitoring of business processes. Volumes of sales are processed in the arrays of information with the help of BI, market statistics, production costs, etc., which allows making strategic decisions.

The main functions of $\mathrm{BI}$ are the following:

- estimation of the current status of the organization;

- detection of tendencies based on current actual indicators of organization and forecasting of potentially possible financial indicators in the future;

- conducting a permanent comprehensive analysis of the organization's activities and timely identification of potential problems;

- prediction of potential outflows of clients in the early stages, when the process can still be prevented; early detection of unprofitable and profitable activities of the organization;

- determination of potential buyers' interest in certain goods (services);

conducting a plan of factor analysis of the current organization's compliance with its strategic objectives.

Each block of solvable tasks with the use of BI consists of the following steps:

stage analysis: it is the estimation of the current infrastructure of the enterprise, data sources and harmonization of functional requirements and use of the formation of various requests/reports that the BI system should provide;

- designing: it is the clarification of the number of actual and potential users of the BI system, specifying the sources of data, business applications and coordination of functional requirements;

- stage of implementation: it is the development of the electronic model of enterprise BI, which includes data warehouse algorithmizing, OLAP cubes, metadata layer, documenting;

- implementation phase: it is the training for all users of the BI system, which implements verification tasks for understanding, validating algorithms and debugging BI;

- stage of experienced work: it is the assessment of system compliance with the primary requirements and further introduction of business analysis and industrial exploitation.

BI systems are based on rich capabilities for constructing user-defined queries, generating flexible reports and simple processing of results directly by managers and analysts who are not IT professionals.

As practice shows, it is difficult to take into account all the arguments of business elements. There is a need of technology that will continuously control the basic elements: product 
relevance, pricing policy, unoccupied market sectors, etc. Modern information technology allows receiving and quickly handling flows of economic and social information. As a result of the combination of BI technologies and smart-analytics, a number of information and analytical systems have been built, allowing one to monitor and make managerial decisions automatically.

Smart Analytics is a full-featured computing system that allows users to begin making full use of powerful business analysis tools in short terms. Technology is based on the software and hardware capabilities of information systems, knowledge, skills and research achievements in the field of mathematical sciences and the experience of companies.

It is reasonable to wonder if the use of smart technologies requires the further study of the software products, which provide the automation of data processing? Even though the answer is positive, the basis is not the study of the smart-programmed product, but the goals set for the desired results. Smart technology is only a smart assistant who, listening to the user, forms up-to-date analytical data arrays.

In his studies, Kravets (2017) observes that the SMART Task Management System through structuring information helps achieve financial goals and needed result, which is surviving.

George Doran in his work "There's a SMART Way to Write Management's Goals and Objectives" considers the word "smart" as a component of the initial letters of the abbreviation:

- $\quad$ specific is the purpose;

- measurable is a way to measure success;

- achievable means the goal should be within the reach;

- relevant is the achievement of the goal, common vision of the goals by different workers;

- time-bound is estimated target time.
So, according to Kravets (2017), SMART analysis provides a simple and clear framework for defining goals and objectives. The convenience of use is the reason of the popularity of the system. It can be used by anyone and anywhere and does not require special skills in setting tasks.

The solution of business issues through SMART technologies is based on analytical data that form the basis of building a common picture. Based on the development of the company "Artwel", the storage of analytical data provides integrated BI solutions that combine the functional components of business management technologies:

- Data Warehouse and Data Marts are general databases of large enterprises that are structured according to the structural units. The feature of the shown data is to provide information in a convenient form for users;

- OLAP analysis systems are analytical data processing tools in real time, for example, the sale of a given product in real time and the influence of factors affecting key indicators;

- Data Integration and Synchronization Tools (ETL) are a software module that provides data transfer from off-lines and remote sources of information with the corresponding transformation of the array structure;

- Knowledge Detection (Data Mining) is a module for detecting patterns in continuously interacting data arrays that can lead to the formation of new knowledge;

- Query and Reporting tools is a module for creating queries and obtaining information with the possibility of detailing.

BPMS monitoring tools are based on the Business Activity Monitoring (BAM) technology and are focused primarily on mid-level and senior management needs.

BAM technology is defined as a real-time technology and provides regular information, current analysis and alarm generation. BAM supports all of this, based on the data from the "sensors", which in this case are called key performance indicators. 
In the course of its work, BAM components process the events that occur during execution of instances of business processes. On the basis of the information on the events of the means of monitoring the business activity, the various reports are formed.

- It will be expedient to apply means of monitoring of smart analytics for the economic direction experts in research analytical work. Correspondingly, it is possible to track emerging problems and errors in business processes. Smart system carries out the output of warnings and error messages and the fall of indicators.

- A list of computer software for automating statistical data research and making smart analytical solutions should be considered. Attention has been paid to the main components of computer analytical programs, namely databases, individuality of reception of a report, connections between elements of analytical data, reasonable automatic analytics and others.

\section{IBM Smart Analytics System}

The IBM Smart Analytics System platform is positioned as a "Performance Management" tool. Management implies the presence of a managed object that can be discarded in different directions by offering it automatically or by observing certain elements of the smart business analytical study. Thus, the manager can follow the advice and make an effective decision. Smart Analytics System is the concept of "everything in one". This is a complex and fully integrated software and hardware solution for deploying information-analytical systems to the scale of an organization or large enterprise. It includes all the necessary tools for deploying a turnkey information and analytical system from business intelligence tools to deployment of data warehouses, including IBM DB2 DBMS.

The work of the Smart Analytics System is based on the reception of information from various sources in the form of both structured and unstructured data. The Data Import module has the ability to get information from unstructured
Microsoft Office documents, audio files and video files. For example, in many text documents, there is the line "total amount", followed by the sum of the words. Ordinary business intelligence tools cannot handle this information. At the same time, one can structure and, of course, visualize, and use it when planning any content with Smart Analytics System.

\section{Microsoft BI}

Microsoft BI is a set of products that allow organizations to make decisions based on reliable information from internal and external data sources. From the point of view of the options for conducting analytical activity, there are three possible scenarios:

- personal;

- collective;

corporate analytics.

Smart-BI-Metrika develops business intelligence projects, through which customers receive:

- single piece of information and analytical system for obtaining accurate, complete and timely information, its in-depth analysis and subsequent adoption of the right decisions;

- interactive reports and dashboards that reveal the main indexes in business processes;

- $\quad$ high awareness of business processes;

- monitoring the realization of company goals through measurable indicators.

Power BI reports on the data of CRM systems, Google Analytics and the most commonly used CIS 1C accounting system have been created by the authors.

\section{General features}

These are as follows:

- power BI dashboards and reports, SharePoint Insights dashboards; 
- data Mining Add used to intelligently analyze data in the office system ETL (extract, convert and load data) - SQL Server Integration Services;

- metadata management system and data quality;

- system for analyzing the relationships between components of an analytical solution - applications;

- Performance Point Dashboards Designer, a tool for creating performance charts and interactive charts on SharePoint Portal.

\section{Smartanalytics}

Network intelligent analytical resource based on business intelligence management and Visual Discovery, Power BI, Pentaho, Prognoz platform, Excel, SQL Server Reporting \& Analysis Services based on SQL Server, Oracle, PostgreSQL, MySQL, Hadoop, NoSQL data management systems.

Software integration policy on Objective-C mobile platforms, Android SDK tools, Universal Window Platform are also supported. The main benefits of Smartanalytics are the data visualization, data management and analytics extensions. The system converts imported data, which allows one to display information conveniently and make strategic decisions with confidence that can bring business to a new level.

General features of Smartanalytics are:

- intelligent processing of large data from internal and external sources;

- automated data collection from internal and external sources including internet portals;

- business intelligence and visual discovery solutions, which are based on pre-installed knowledge;

- visualization of data and infographics of various kinds of reports and presentations including geoanalytics; comprehensive software solutions based on economic and mathematical modeling and machine learning, time series analysis, dynamics design, econometric modeling, script analysis (what, if and for what);

- the organization of automated workplaces such as "mobile office for top managers", individual programs for internal and external users.

\section{RESULTS OF EMPIRICAL ANALYSIS}

The created conceptual scheme of the effective management is demonstrated on the simple example of optimal choice of electromobile. In order to investigate sales on Ukrainian market of electric vehicles the following factors have been considered: 1 - Year of production; 2 - Mileage; 3 - Price; 4 - Battery status in \%; 5 - Consumption for $100 \mathrm{~km} ; 6$ - Maximum distance at one charge, $\mathrm{km} ; 7$ - Charging time, hr.; 8 - Economy, 10 points scale; 9 - Prestige, 0-10 points; 10 - Comfort, $0-10$ points; 11 - Average rating of the former car according to the previous 3 parameters, $0-10$ points; 12 - Year of purchasing the vehicle.

All information is given in Table 1. The statistical sample consists of 33 objects (vehicles) and includes 12 different types of characteristics.

In order to determine the degree of interconnection and the interaction between the given factors, a correlation analysis has been conducted, which resulted in a correlation matrix (Table 2).

Analysis of the obtained correlation matrix makes it possible to come to the following conclusions:

1. The most related factors are 5 and 6 (Consumption per $100 \mathrm{~km}, \$$ and Maximum distance at 1 charge, $\mathrm{km}) ; r_{56}=0.98$.

2. The following factors are the most influential on the price of electric cars: $r$ (price; consumption) $=r_{35}=0.84 ; r$ (price; $\max$ distance) $=r_{36}=0.83$;

3. The least significant for the price of an electric vehicles are the following factors: Year 


\section{Plot of Means Each Cluster}

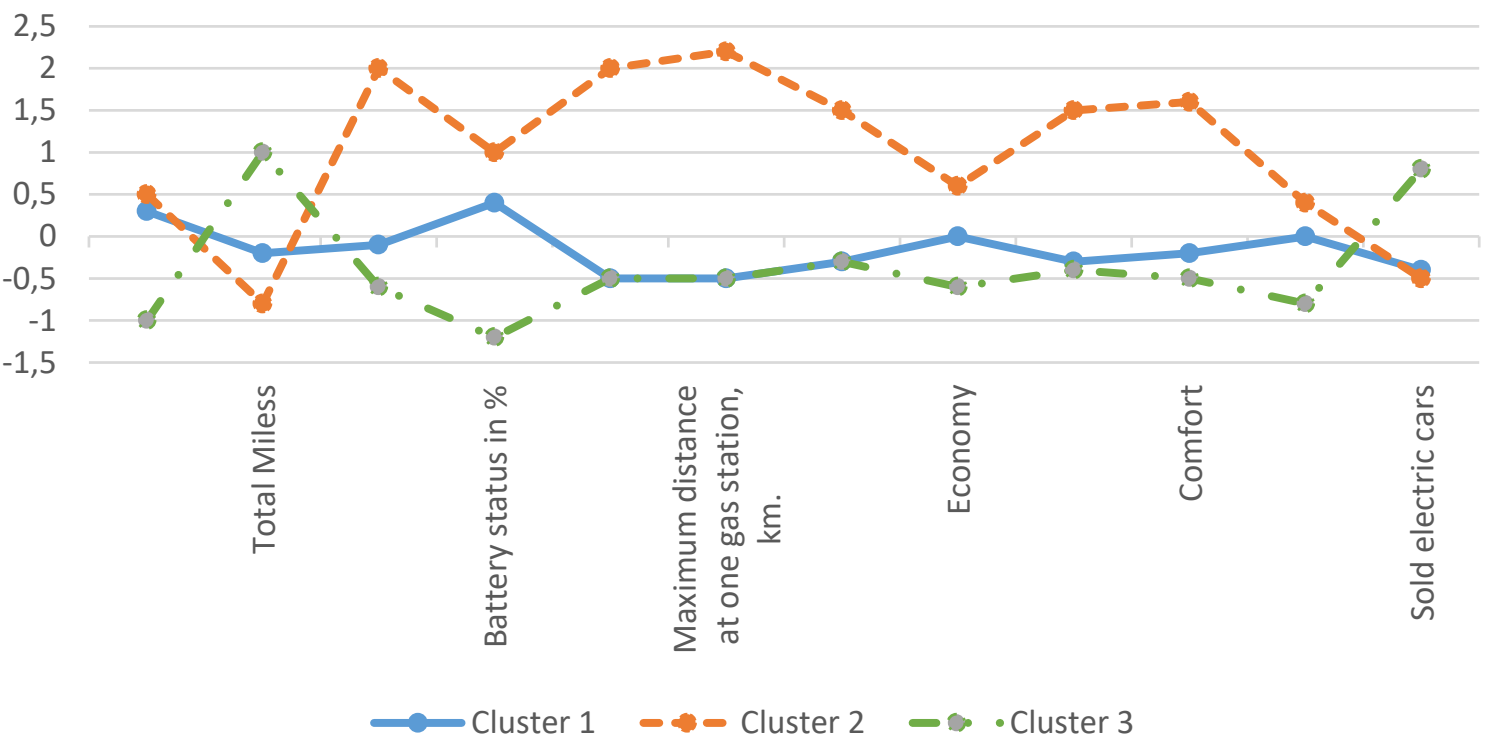

Figure 4. Cluster analysis results

of purchasing the vehicle and Economy 10 points scale: $r$ (price; Year of purchasing the vehicle) $=r_{3,12}=-0.16 ; r$ (price; Economy) $=r 39=0.16$;
4. Almost identical in the opinion of customers of electric vehicles are such factors as Prestige and Comfort: $r$ (Prestige; Comfort) $=r_{9,10}$ $=0.81$.

Table 1. Statistics of input data of technical parameters and comparative characteristics of key parameters of electric vehicles

Source: Compiled by the authors.

\begin{tabular}{|c|c|c|c|c|c|c|c|c|c|c|c|c|}
\hline $\bar{U}$ & 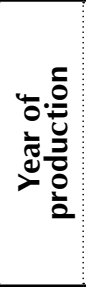 & 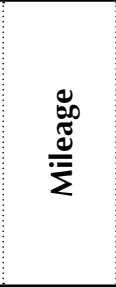 & : & 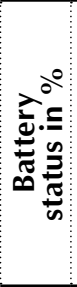 & 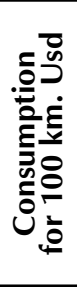 & 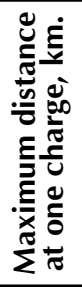 & 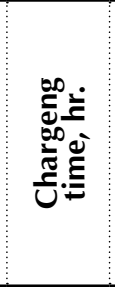 & 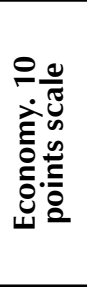 & 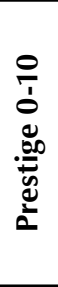 & 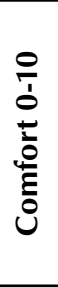 & 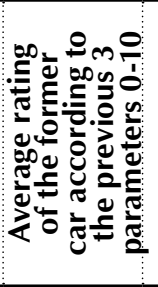 & 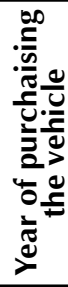 \\
\hline Nissan Leaf-1 & 2011 & 98,000 & 10,500 & 75 & 19 & 120 & 6 & 9 & 7 & 7 & 4 & 45 \\
\hline Nissan Leaf-2 & 2013 & 94,535 & 13,800 & 83 & 25 & 140 & 3 or 0,3 & 10 & 7 & 7 & 3 & 50 \\
\hline Tesla model $x$ & 2016 & 8,678 & 95,000 & 100 & 75 & 450 & 42 or 4 & 10 & 10 & 10 & 5 & 3 \\
\hline $\begin{array}{l}\text { Smart Fortwo electric } \\
\text { drive C } 451\end{array}$ & 2014 & 34,567 & 13,200 & 93 & 20 & 130 & 6 or 1 & 9 & 6 & 7 & 4 & 1 \\
\hline Nissan E-NV200 & 2014 & 41,587 & 22,500 & 96 & 25 & 160 & 3 or 0,3 & 10 & 8 & 8 & 5 & 2 \\
\hline Tesla Model S & 2012 & 8,600 & 35,000 & 100 & 45 & 350 & 10 or 1 & 10 & 9 & 9 & 6 & 3 \\
\hline Nissan Leaf SV & 2015 & 16,000 & 18,400 & 96 & 25 & 173 & 3 or 0,3 & 10 & 7 & 8 & 5 & 23 \\
\hline Toyota Rav 4 EV & 2013 & 113,000 & 27,700 & 81 & 35 & 220 & 8 & 9 & 7 & 8 & 4 & 2 \\
\hline Ford focus electric & 2014 & 41,000 & 17,500 & 95 & 25 & 120 & 3 & 9 & 7 & 8 & 5 & 1 \\
\hline Fiat $500 \mathrm{e}$ & 2014 & 69,000 & 13,800 & 89 & 25 & 145 & 3 & 8 & 7 & 7 & 5 & 5 \\
\hline Renault Zoe & 2012 & 241,000 & 12,500 & 91 & 25 & 130 & 3 & 7 & 7 & 7 & 4 & 2 \\
\hline Tesla Model 3 & 2018 & 5,000 & 75,000 & 100 & 80 & 440 & 1 & 9 & 8 & 8 & 6 & 2 \\
\hline Volkswagen e-Golf & 2014 & 34,000 & 23,500 & 93 & 30 & 160 & 4 & 9 & 7 & 7 & 5 & 2 \\
\hline BMW i3 & 2014 & 37,000 & 27,800 & 94 & 30 & 150 & 3 & 9 & 9 & 9 & 6 & 2 \\
\hline Renault Kangoo & 2014 & 64,000 & 13,200 & 89 & 20 & 140 & 3 & 9 & 6 & 7 & 5 & 1 \\
\hline
\end{tabular}


Table 1 (cont.). Statistics of input data of technical parameters and comparative characteristics of key parameters of electric vehicles

\begin{tabular}{|c|c|c|c|c|c|c|c|c|c|c|c|c|}
\hline נ̇ & 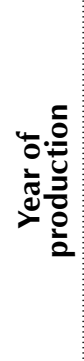 & 总 & $\frac{\mathbb{U}}{2}$ & 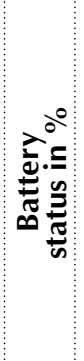 & 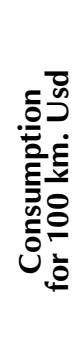 & 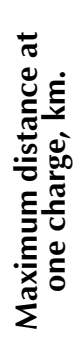 & 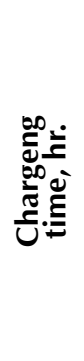 & 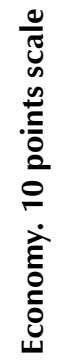 & 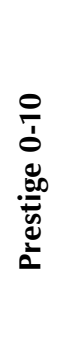 & $\begin{array}{l}\frac{0}{1} \\
0 \\
\frac{t}{0} \\
\frac{0}{0}\end{array}$ & 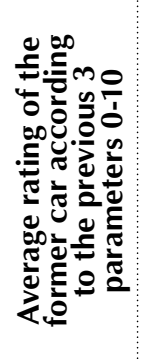 & 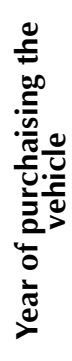 \\
\hline Mitsubishi I miEV & 2012 & 18,000 & 9,500 & 85 & 15 & 125 & 6 & 9 & 7 & 7 & 5 & 2 \\
\hline $\begin{array}{l}\text { Mitsubishi Outlander } \\
\text { PHEV }\end{array}$ & 2015 & 117,000 & 26,600 & 81 & 10 & 52 & 3 & 9 & 7 & 7 & 4 & 2 \\
\hline Renault Fluence & 2011 & 88,000 & 11,600 & 37 & 15 & 67 & 2 & 7 & 7 & 7 & 5 & 2 \\
\hline Renault twizy & 2014 & 67,000 & 7,500 & 88 & 15 & 100 & 6 & 8 & 7 & 7 & 5 & 2 \\
\hline Kia Soul EV & 2014 & 44,000 & 19,800 & 97 & 28 & 120 & 3 & 8 & 7 & 7 & 5 & 2 \\
\hline Hyndai loniq & 2018 & 65,000 & 36,500 & 100 & 30 & 140 & 3 & 8 & 7 & 7 & 5 & 1 \\
\hline Chevrolet Bolt & 2017 & 22,000 & 39,000 & 92 & 55 & 350 & 3 & 8 & 7 & 7 & 5 & 1 \\
\hline BMW i8 & 2018 & 15,000 & 67,000 & 95 & 10 & 40 & 1 & 8 & 8 & 8 & 6 & 2 \\
\hline $\begin{array}{l}\text { Mercedec B-class } \\
\text { electric drive }\end{array}$ & 2014 & 76,000 & 22,000 & 87 & 25 & 145 & 3 & 7 & 9 & 8 & 6 & 2 \\
\hline Volkswagen e-UP & 2013 & 36,000 & 12,700 & 94 & 15 & 120 & 1 & 8 & 7 & 8 & 5 & 2 \\
\hline Citroen C-Zero & 2012 & 12,000 & 9,600 & 81 & 30 & 110 & 3 & 8 & 7 & 7 & 5 & 1 \\
\hline Audi E-tron & 2017 & 9,700 & 49,900 & 99 & 25 & 190 & 3 & 8 & 8 & 7 & 5 & 2 \\
\hline Opel Ampera-E & 2013 & 241,000 & 18,600 & 89 & 15 & 60 & 3 & 8 & 7 & 7 & 4 & 2 \\
\hline Citroen E-Mehari & 2018 & 5,790 & 35,500 & 90 & 35 & 160 & 3 & 7 & 7 & 7 & - & 3 \\
\hline Jac iEV6E & 2017 & 3,400 & 15,500 & 90 & 25 & 140 & 2 & 8 & 7 & 7 & 5 & 1 \\
\hline Ford Fusion & 2014 & 65,000 & 13,500 & 67 & 15 & 80 & 1 & 6 & 7 & 7 & 5 & 2 \\
\hline Tesla Semi & 2018 & 1,200 & 125,000 & 100 & 180 & 890 & 6 & 8 & 8 & 9 & 6 & 2 \\
\hline Chevrolet Spark EV & 2012 & 29,000 & 8,800 & 59 & 20 & 120 & 2 & 6 & 7 & 7 & - & 3 \\
\hline
\end{tabular}

Table 2. Correlation matrix of the given factors

Source: Compiled by the authors.

\begin{tabular}{|c|c|c|c|c|c|c|c|c|c|c|c|c|}
\hline No & 1 & 2 & 3 & 4 & 5 & 6 & 7 & 8 & 9 & 10 & 11 & 12 \\
\hline 1 & 1.00 & - & - & - & - & - & - & - & - & - & - & - \\
\hline 2 & -0.43 & 1.00 & - & - & - & - & - & - & - & - & - & - \\
\hline 3 & 0.67 & -0.36 & 1.00 & - & - & - & - & - & - & - & - & - \\
\hline 4 & 0.55 & -0.24 & 0.44 & 1.00 & - & - & - & - & - & - & - & - \\
\hline 5 & 0.45 & -0.31 & 0.84 & 0.34 & 1.00 & - & - & - & - & - & - & - \\
\hline 6 & 0.42 & -0.35 & 0.83 & 0.38 & 0.98 & 1.00 & - & - & - & - & - & - \\
\hline 7 & 0.05 & -0.14 & 0.44 & 0.20 & 0.30 & 0.37 & 1.00 & - & - & - & - & - \\
\hline 8 & -0.01 & -0.18 & 0.16 & 0.49 & 0.11 & 0.20 & 0.38 & 1.00 & - & - & - & - \\
\hline 9 & 0.21 & -0.26 & 0.58 & 0.31 & 0.37 & 0.43 & 0.55 & 0.22 & 1.00 & - & - & - \\
\hline 10 & 0.10 & -0.27 & 0.50 & 0.37 & 0.36 & 0.44 & 0.62 & 0.53 & 0.81 & 1.00 & - & - \\
\hline 11 & 0.13 & -0.16 & 0.29 & 0.36 & 0.23 & 0.25 & 0.07 & 0.32 & 0.38 & 0.33 & 1.00 & - \\
\hline 12 & -0.26 & 0.14 & -0.17 & -0.14 & -0.09 & -0.08 & -0.01 & 0.35 & -0.11 & 0.06 & -0.21 & 1.00 \\
\hline
\end{tabular}


The cluster analysis has been carried out using the $\mathrm{k}$-means method for the Euclidean metric with the selection of 3 clusters. Figure 4 clearly shows 3 distinct clusters. The characterization of each of them follows.

The first cluster includes electric cars, which have the average results in all selected indicators. They are the most appropriate for the characteristics of the price - quality. The second cluster consists of the most elite cars with the highest price, minimum mileage and high quality. The third cluster includes low-end budget, high mileage and low-quality vehicles. Representatives of each cluster are shown below.

Cluster 1: Smart Fortwo electric drive C451, Nissan E-NV200, Nissan Leaf SV, Toyota Rav 4 EV, Ford focus electric, Fiat 500e, Volkswagen e-Golf, BMW i3, Renault Kangoo, Mitsubishi
I miEV, Mitsubishi Outlander PHEV, Renault Twizy, Kia Soul EV, Hyundai Ioniq, Chevrolet Bolt, BMW i8, Mercedes B-class electric drive, Volkswagen e-UP, Citroen C-Zero, Audi E-tron, Citroen E-Mehari, Jac iEV6E.

Cluster 2: Tesla model x, Tesla Model S, Tesla Model 3, Tesla Semi.

Cluster 3: Nissan Leaf 1, Nissan Leaf 2, Renault Zoe, Renault Fluence, Opel Ampera-E, Ford Fusion, Chevrolet Spark EV.

For choosing optimal marketing strategy, the most popular modern smart-analytical tool Tableau has been used. Visualization obtained with the use of this program can help buyers understand the connections between all given factors. Some received visualizations are shown in Figure 5 and Figure 6.

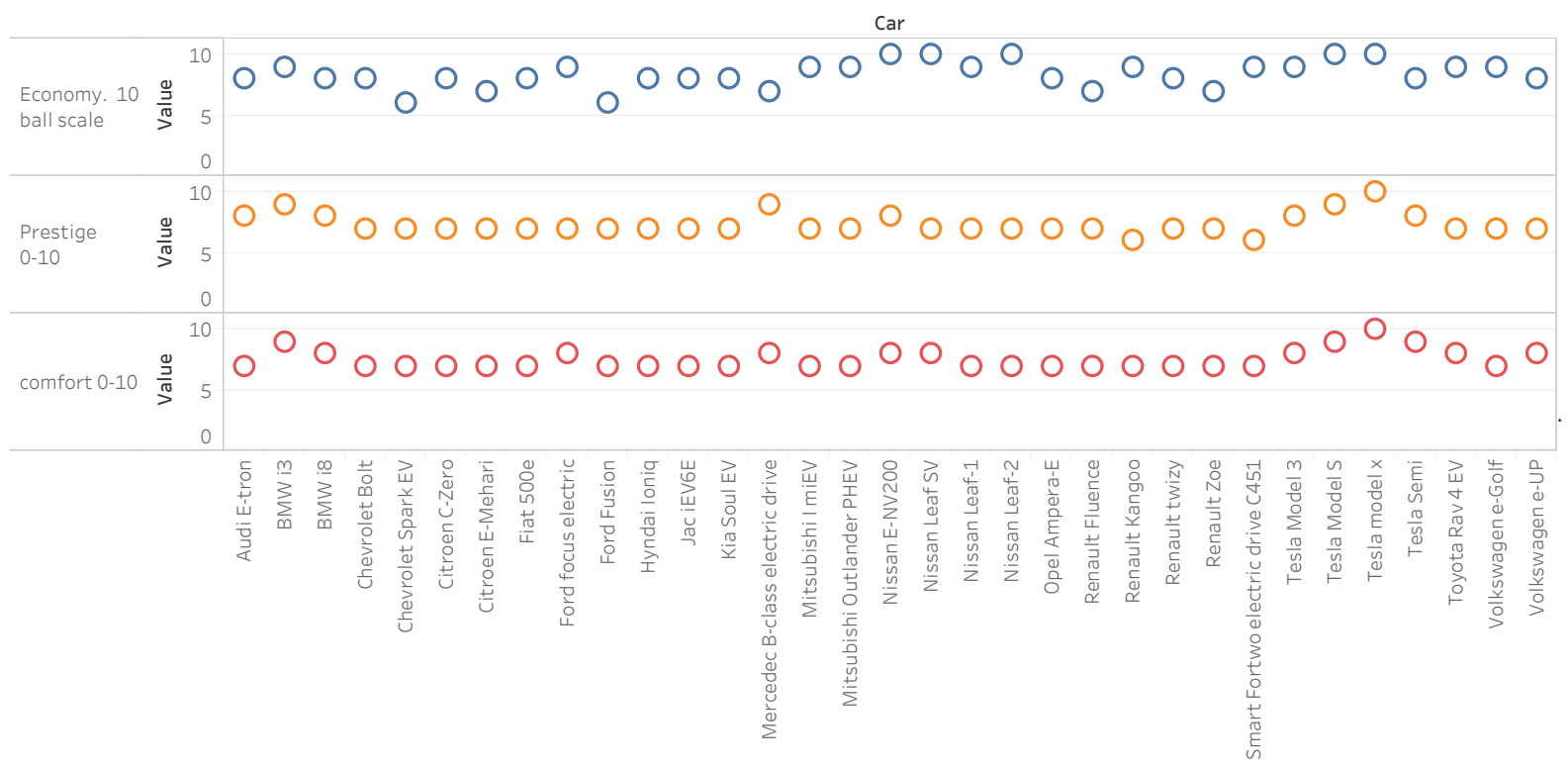

Economy. 10 ball scale, Prestige 0-10 and comfort 0-10 for each Car. Color shows details about Economy. 10 ball scale, Prestige 0-10 and comfort 0-10.

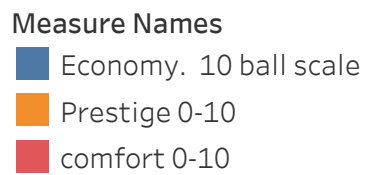

Figure 5. Diagram of dependence of profitability of cars 


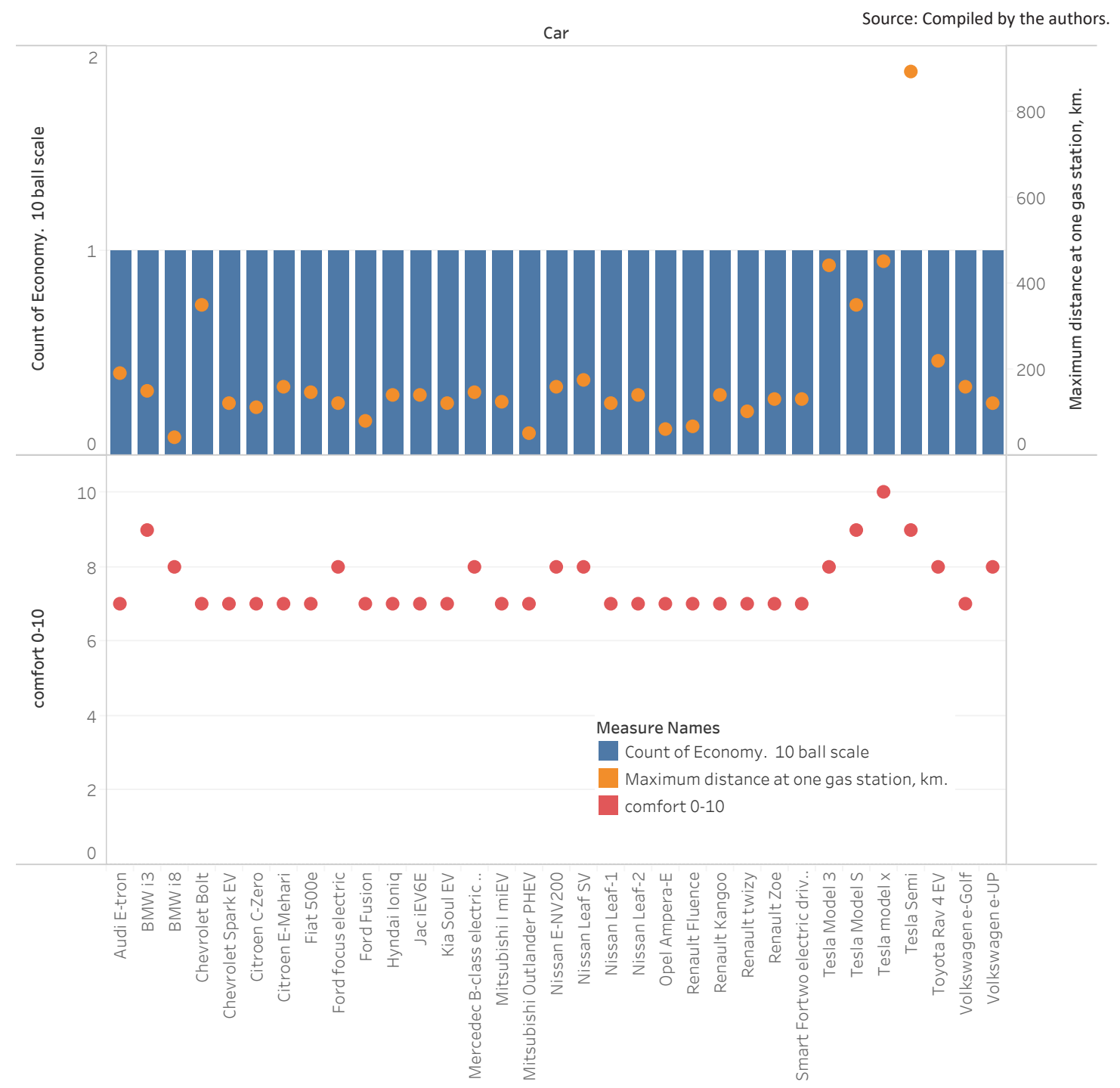

Count of Economy. 10 ball scale, Maximum distance at one gas station, km. and comfort 0-10 for each Car. Color shows details about count of Economy. 10 ball scale, Maximum distance at one gas station, km. and comfort 0-10.

Figure 6. Diagram of correlation between comfort and profitability of vehicles

\section{CONCLUSION}

The results show that electric cars of the lowest price segment with low quality indicators are the most widespread among Ukrainian buyers. The conducted statistical calculations are also confirmed by the marketing agency IRC Group. The most popular electric car among the Ukrainians is the Nissan Leaf, the share of registered Leafs in the total number of electric vehicles in the country accounts for $78 \%$.

It is followed by Ford Focus Electric, Tesla Model S, BMW i3 with a huge backlog. Figure 6 reflects a part of these models, which represent $3 \%$ of the total number of electric cars. The Nissan Leaf and Ford Focus Electric belong to Class H, Tesla Model - to S, the Executive L-Class F, while the BMW i3 is a B-class hatchback.

Such "versatility" indicates the lack of competition in the Ukrainian market of electric cars. Thus, the choice and purchase are primarily based on the price and accessibility. Different models of the same class do not compete for the clients by the means of their design, features, equipment. 


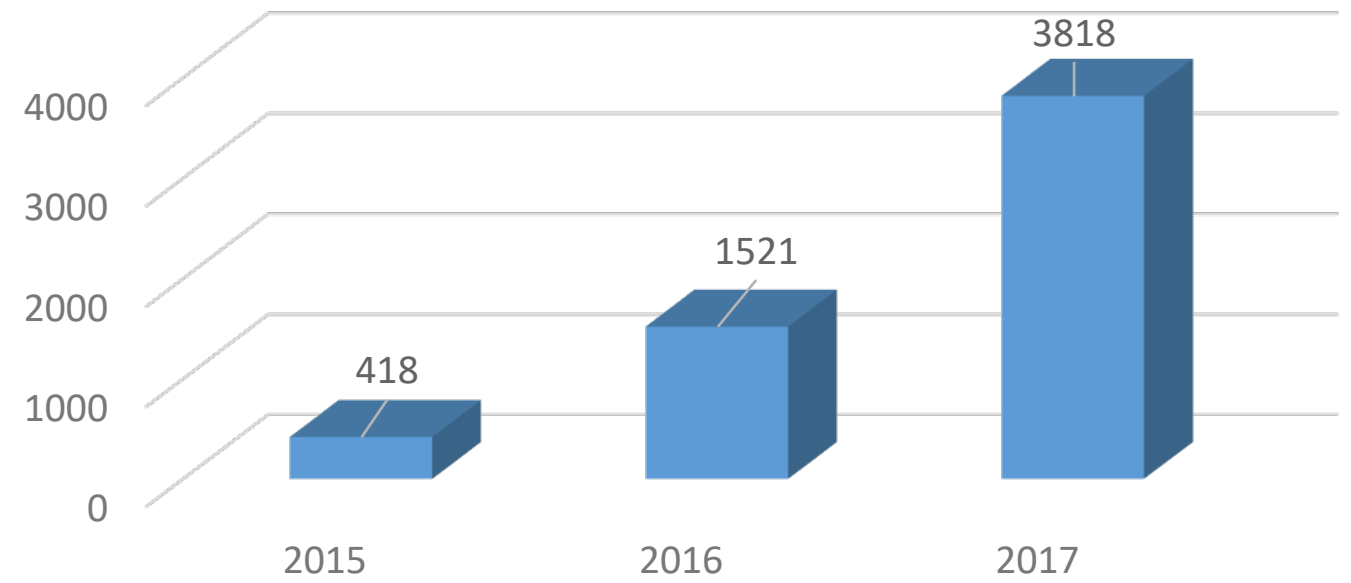

Figure 7. Number of electric cars

The number of electric vehicles in Ukraine has increased by a factor of two or even more. The main reasons for this are the factors presented in the calculations in Table 1. An additional factor in the popularity and rise in the number of electric cars is the adoption of a bill on amendments to the Customs Code of Ukraine in December 2017. It is about the abolition of VAT and excise on the import of electric cars (with the concessional term of one year - until December 31,2018). This is evidenced by the official statistics of the Ministry of Internal Affairs of Ukraine on the first registration of cars in Ukraine.

In Figure 7, there is the statistics provided for January and February 2017, during which the first 196 and 205 electric cars, respectively, were registered in Ukraine. At the same time, during these two months of 2018, 801 electric vehicles were registered.

In conclusion, a methodology for modeling business processes for the adoption of optimal managerial solutions by means of smart analytics have been proposed. Also, it has been demonstrated how it works on the example of optimal choice of electro vehicle. A lot of different statistical, mathematical and analytical methods have been taken into account, which would help to make optimal decisions more quickly and with higher level of quality. This methodology can be used by managers to perform their duties more efficiently.

\section{REFERENCES}

1. Abelein, U., Lochner, H., Hahn, D., 4. Atteslander, P. (2008). Methoden \& Straube, S. (2012). Complexity, quality and robustness-the challenges of tomorrow's automotive electronics. Automation \& Test in Europe Conference \& Exhibition, 870-871. http://dx.doi. org/10.1109/DATE.2012.6176573

2. Afuah, A. (2003). Business Models: A Strategic Management Approach (432 p.). RELIX Management Project $\mathrm{GmbH}$.

3. Artwell (2017). Analytical systems, business intelligence systems. Retrieved from http://www.artwell. $\mathrm{ru} /$ services/analiticheskie-sistemysistemy-biznes-intellekta/ der empirischen Sozialforschung (359 p.). Danuvia Druckhaus, Neuburg a.d. Donau.

5. Baden-Fuller, C. H., \& Morgan, M. S. (2010). Business Models as Model. Long Range Planning, 43(2), 156-171. http://dx.doi. org/10.1016/j.lrp.2010.02.005

6. Basl, J. (2004). The Innovation of Business Processes Based on IS/ ICT and The TOC. Retrieved from http://www.cvis.cz/eng/

7. Bowley, A. L. (1926). Measurements of precision attained in sampling. Bulletin of the International Statistics Institute, 22(1), 1-62.

8. Caceres, R. C., \& Paparoidamis, N. G. (2007). Service quality, relationship satisfaction, trust, commitment and business-to-business loyalty. European Journal of Marketing, 41(7-8), 836-867. https://doi. org/10.1108/03090560710752429

9. Chern, C., Anthony, J., \& ChihPing, W. (2015). Introduction to the special issue on Data analytics for marketing intelligence. Information Systems and e-Business Management, 13(3), 399-402. Re- 
trieved from https://link.springer. com/article/10.1007/s10257-0140270-3

10. Chesbrough, H. (2006). Open Business Models: How to Thrive in the New Innovation Landscape (272 p.). Retrieved from https:// hbr.org/product/open-businessmodels-how-to-thrive-in-thenew-innovation-landscape/4273HBK-ENG

11. Colgate, M., \& Lang, B. (2001). Switching barriers in consumer markets: An investigation of the financial services industry null. Journal of Consumer Marketing, 18(4), 332-347. Retrieved from https://www.deepdyve.com/lp/ emerald-publishing/switchingbarriers-in-consumer-markets-aninvestigation-of-the-MGRZAF44SF

12. Cronin, J. J., Brady, M. K., \& Hult, G. T. (2000). Assessing the effects of quality, value, and customer satisfaction on consumer behavioral intentions in service environments. Journal of Retailing, 76(2), 193-218. https://doi.org/10.1016/ S0022-4359(00)00028-2

13. Dabbolkar, P. A. (1995). A contingency framework for predicting causality between customer satisfaction and service quality. Advances in Consumer Research, 22(1), 101-108. Retrieved from http://acrwebsite.org/volumes/7677/volumes/v22/NA-22

14. DaSilva, C. M., \& Trkman, P. (2014). Business model: What it is and what it is not. Long Range Planning, 47(6), 379-389. https:// doi.org/10.1016/j.lrp.2013.08.004

15. Dombrowski, U., \& Engel, C. (2014). Impact of Electric Mobility on the After Sales Service in the Automotive Industry. Procedia CIRP, 16, 152-157. http://dx.doi. org/10.1016/j.procir.2014.01.022

16. Draft Law on Amendments to the Tax Code of Ukraine to ensure the balance of budget revenues in 2018. Retrieved from http:// w1.c1.rada.gov.ua/pls/zweb2/ webproc4_1?pf3511=62878

17. Doran, G. T. (1981). There's a S.M.A.R.T. Way to Write Management's Goals and Objectives. Management Review, 70, 35-36.

18. Forster, C., Zapp, M., Aelker, J., Westkämüer, E., \& Bauernhansl, T. (2013). Collaborative value chain management between automotive and semiconductor industry: an analysis of differences and improvement measures. Procedia CIRP, 12, 312-317. http://dx.doi. org/10.1016/j.procir.2013.09.054

19. Harrington, H. J. (1991). Business Process Improvement (1st ed.) (274 p.). McGraw-Hill Education.

20. IBM Smart Analytics System (2018). Retrieved from https:// www.itcentralstation.com/products/ibm-smart-analytics-system

21. Insys: Analytical Systems (2017). Retrieved from http:// www.insys-solutions.ru/index. php?option=com_content\&view= article\&id=99\&Itemid $=94$

22. Ittner, C. D., \& Larcker, D. F. (1998). Innovations in Performance Measurement: Trends and Research Implication. Journal of Management Accounting Research, 10(2), 205-238. Retrieved from https://papers.ssrn.com/sol3/papers.cfm?abstract_id $=137278$
23. Johns, P., \& Van Doren, D. (2010). Competitive intelligence in service marketing: a new approach with practical application, marketing intelligence \& planning. European Journal of Marketing, 28(5), 551-570. https://doi. org/10.1108/02634501011066492

24. Kravets, F. (2017). What are SMART tasks and how do they work. Retrieved from https:// equity.today/chto-takoe-zadachismart-i-kak-oni-rabotayut.html

25. Magretta, J. (2010). Why Business Models Matter. Harvard Business Review, 80(5), 86-92.

26. Massanel, C. R., \& Ricart, J. E. (2010). From strategy to business models and onto tactics. Long Range Planning, 43, 195 215. https://doi.org/10.1016/j. lrp.2010.01.004

27. Osterwalder, A., \& Pignieur, Y. (2009). Business Model Generation, Self-Published (288 p.). Retrieved from http://gostracker.xyz/viewtopic.php? $\mathrm{t}=3649602$

28. Rachok, N. (2018). Record growth in sales of electric vehicles. Retrieved from http://news. infocar.ua/v_ukraine_zafiksirovan_rekordnyy_rost_prodaj_elektromobiley_120223.html

29. Sydorova, A. V., \& Kurnosova, O. A. (2012). Process innovations within the contemporary theory of innovations. Actual Problems of Economics, 11(137), 49-57.

30. Teece, J. D. (2010). Business Models, Business Strategy and Innovation. Long Range Planning, 43(2), 172-194. http://dx.doi. org/10.1016/j.lrp.2009.07.003 